International Journal of Mechanical Engineering and Technology (IJMET)

Volume 11, Issue 5, May 2020, pp. 34-47, Article ID: IJMET_11_05_004

Available online at http://www.iaeme.com/ijmet/issues.asp?JType=IJMET\&VType $=11 \&$ IType $=5$

(C) IAEME Publication

Journal Impact Factor (2020): 11.2184 (Calculated by GISI) www.jifactor.com

ISSN Print: 0976-6340 and ISSN Online: 0976-6359

\title{
OPTIMIZATION OF AERO ENGINE UTILIZATION THROUGH IMPROVED ESTIMATION OF REMAINING USEFUL LIFE (RUL) OF ON CONDITION (OC) PARTS
}

\author{
Kotha Vidyasagar \\ Centre for Propulsion Engineering, School of Aerospace, Cranfield University, \\ Cranfield, Bedfordshire, United Kingdom. \\ Author E-mail: vidyasagar.kotha@cranfield.ac.uk, kothavidyasaga@gmail.com
}

\begin{abstract}
Gas Turbine Operators and Maintainers face the challenge of increasing the operational life, availability, and reliability of Aero Engine during the operations amid the advancements in the technology for the speed, Power, SFC, and Comfort which led to closing in the safety margins and increasing in the failure rate of Aero Engines, and low serviceability of aero engines due to the rapid increase in demand and expansion of the aircraft fleet by the various airlines for various reasons which led to increase in downtime and lead time of serviceability of Aero Engines. This study focuses on the inherent Aero Engine deterioration caused due to various Gas Turbine Faults or Physical Problems and how Performance, Trend, and Systems Monitoring contain this deterioration and contribute to the optimization of aero engine utilization. The purpose of this paper is to present the importance of accurate estimation of Remaining Useful Life (RUL) of On Condition (OC) Parts and how it optimizes aero engine life. The benefits associated with the introduction of a novel estimation of RUL of OC Parts are also presented. A Standardized Replacement Model (SRM), which improves the estimation of RUL of OC Parts, is proposed for optimization of Aero Engine Utilization.
\end{abstract}

Keywords: Remaining Useful Life (RUL), On Condition (OC) Parts, Deterioration, Degradation, Gas Turbine (GT) Faults, Life Limited Parts (LLPs), Estimation, Optimization.

Cite this Article: Kotha Vidyasagar, Optimization of Aero Engine Utilization through Improved Estimation of Remaining Useful Life (RUL) of On Condition (OC) Parts. International Journal of Mechanical Engineering and Technology. 11(5), 2020, pp. 34-47.

http://www.iaeme.com/IJMET/issues.asp?JType=IJMET\&VType=11\&IType=5

Published by International Association of Engineering and Management Education (IAEME). This is the Author Accepted Manuscript issued with:

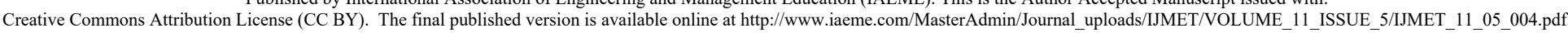
Please refer to any applicable publisher terms of use. 


\section{INTRODUCTION}

Maintenance involves a range of preventive and corrective actions taken to sustain and enhance the use of equipment. These actions are typically dependent on predefined procedures according to the maintenance task. The inherent reliability of gas turbines does not rule out breakdowns and performance deterioration due to the hostile operating environment and the cycle sensitivity to component degradation. Thus the aim of gas turbine maintenance is not only to prevent these breakdowns but also to recover performance at a minimum cost. Aero engine is the core component of aircraft and monitoring and diagnosis of faults of aero engine system in time can avoid the accident occurring effectively and reduce huge losses due to accidents [1]. An aircraft engine is a complex and advanced system that has to meet high standards of safety and reliability. Regular maintenance with disassembling and replacement of parts is therefore required Maintenance costs typically account for between ten and twenty percent of the total aircraft operating costs. Maintaining an aircraft engine is not only complex and time-consuming but also very expensive [2]. It may account for approximately $30 \%$ of the total maintenance cost for an aircraft. It is therefore of great importance to be time-efficient and to decrease costs without compromising safety. It is also very important to avoid performing excessive work and/or component replacement, which would both reduce engine availability and lead to the discarding of components with life remaining.

Maintaining a fleet of aircraft also presents challenges from a business perspective since the goals of decreasing maintenance and operations costs may conflict with desired service levels and safety levels. Maintenance and how it is performed is therefore of the utmost importance. While an engine is being maintained, it is not available for operation. This can have serious consequences if the engine in question is needed for operation in, say, a combat situation

It is therefore very important to determine exactly what maintenance is needed and to avoid excessive maintenance. There are three different categories of components in an aircraft engine: life-limited parts (LLPs), on-condition parts (OC parts), and consumables (Fig. 2). LLPs have a fixed lifespan and must be exchanged when they have reached that limit since they are safety critical (i.e. any failure of that part could cause an engine breakdown so serious that it would cause the aircraft to crash). OC parts are "stochastic" parts that are approved for further use as long as their condition is within approved limits. It is also possible that an LLP that has not reached its life limit cannot be approved for continued service because of other life-limiting issues such as cracks or fretting. An LLP can thus also be evaluated as an OC part. The third group of components, "consumables", represents a small group of components that are exchanged each time they are removed from the engine.
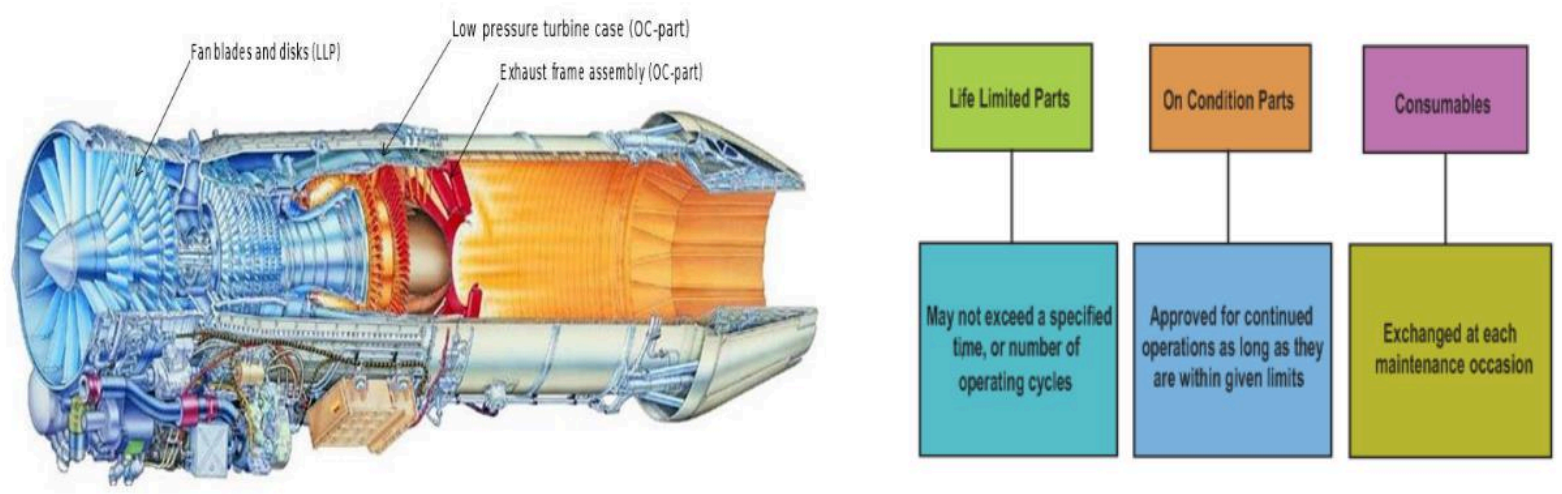

Figure 1 Typical Aero Engine with examples of LLPs \& OC Parts Figure 2 Categories of Components/Parts in Aero Engines 


\subsection{Maintenance Types}

Generally, there are two types of maintenance in use (Fig 3):

\subsubsection{Corrective Maintenance}

Corrective maintenance can be defined as the maintenance which is required when an item has failed or worn out to bring it back to working order. Corrective maintenance is the program focused on the regular task that will maintain all the critical machinery and the system in optimum operating conditions. The major objectives of the corrective maintenance program are to eliminate breakdown, eliminate deviation, eliminate unnecessary repairs, and optimize all the critical planned system.

\subsubsection{Preventive Maintenance}

It is the maintenance where the equipment is maintained before breakdown occurs. It is performed in an attempt to avoid failures, unnecessary production loss, and safety violations. Preventive maintenance is effective in preventing age-related failures of the equipment. For random failure patterns that amount to 80 percent of the failure patterns, conditioning monitoring proves to be effective. The effectiveness of a preventive maintenance schedule depends on Reliability Centered Maintenance (RCM) Analysis which it was based on, and the ground rules used for cost-effectivity. Predetermined Maintenance and Condition Based Maintenance is part of Preventive Maintenance.

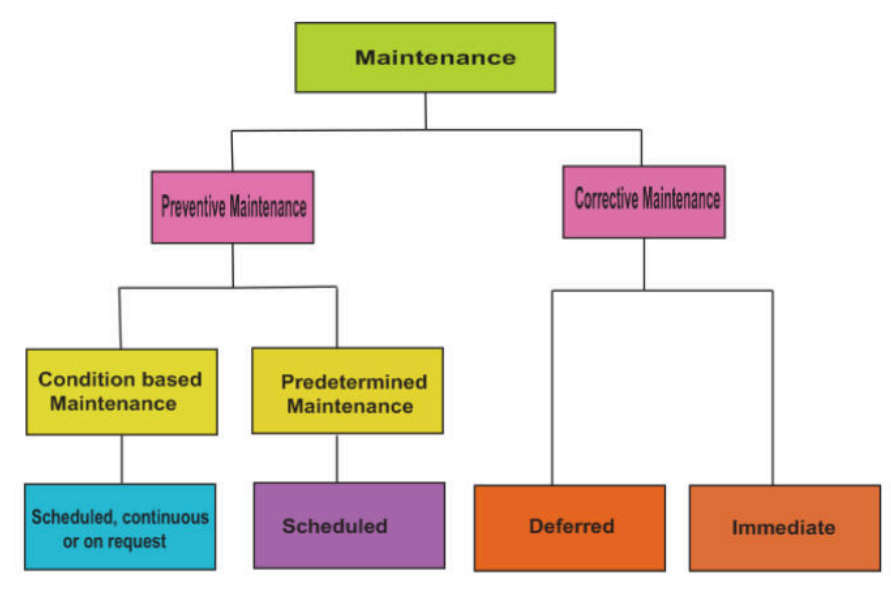

Figure 3 Aero Engine Maintenance Types

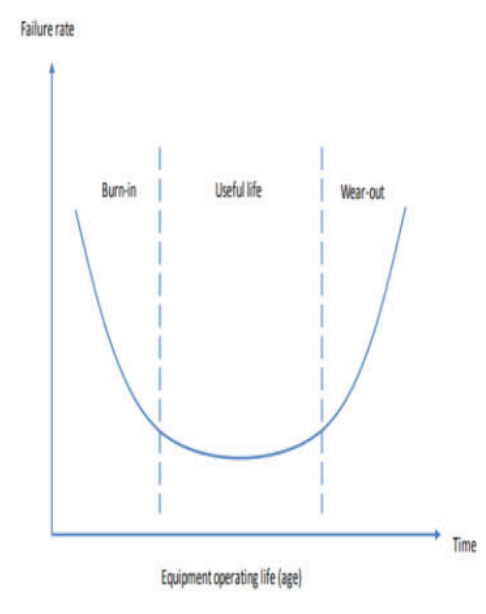

Figure 4 Bathtub Curve

\subsubsection{Predetermined Maintenance}

Predetermined maintenance is a newer maintenance technique that is defined as preventive maintenance carried out in accordance with established intervals of time or number of units of use, but without previous condition investigation. Predetermined maintenance (also called time-based maintenance, planned maintenance, or periodic-based maintenance) uses a periodic interval to perform preventive maintenance regardless of the health status of the physical asset [3]. Predetermined maintenance, maintenance at predetermined time intervals, can bring the system to an as-good-as-new state. In predetermined maintenance, maintenance decisions are based on failure time analysis. Predetermined maintenance assumes that a component's failure behavior is predictable, that is, a component must have a predictable wear-out stage to be eligible for predetermined maintenance. This assumption tends to be based on conclusions from the analysis of hazards or failure rate trends, also called bathtub curves (Fig 4). 


\section{Bathtub Curve}

Failure trends are normally divided into three identifiable regions. The first region refers to a burn-in period, also called the infant-mortality region, which is the period immediately after manufacture or overhaul in which there is a relatively high probability of failure. The second region exhibits a constant and relatively low failure probability; this period can be identified as useful life. The third region is a wear-out region, in which the probability of failure increases rapidly. The below figure depicts the classical bathtub curve.

\subsubsection{Condition-based Maintenance}

Condition-based maintenance is defined as preventive maintenance based on performance and/or parameter monitoring and subsequent actions. In 1974 condition-based maintenance was introduced in order to maximize the effectiveness of preventive maintenance decision making. It is a maintenance program that recommends maintenance actions based on the information collected through condition monitoring. Condition-based maintenance also attempts to avoid unnecessary maintenance tasks by taking maintenance actions only when there is evidence of abnormal behavior of a physical asset and is designed to detect the onset of failure.

Condition-based maintenance is commonly divided into two classes of tasks: diagnosis and prognosis [3]. Diagnosis is the process of finding the fault after or in the process of the fault occurring in the system. Prognosis is the process of predicting the future failure of a system by analyzing the current and previous history of the operating conditions of the system or by monitoring the deviation rate of the operation from the normal conditions.

\section{MAINTAINABILITY, AVAILABILITY, AND RELIABILITY}

\subsection{Reliability}

Maintenance costs and availability are two of the most important concerns to the equipment owner. A maintenance program that optimizes the owner's costs and maximizes equipment availability must be instituted.

Probability of not being forced out of service when the unit is needed includes forced outage hours $(\mathrm{FOH})$ while in service, while on reserve shutdown and while attempting to start normalized by period hours $(\mathrm{PH})[10]-$ units are \%:

Reliability $=(1-\mathrm{FOH} / \mathrm{PH}) *(100 \%)$

Where $\mathrm{FOH}=$ total forced outage hours,

$\mathrm{PH}=$ period hours

Reliability is basically a design feature and even with the best of the maintenance techniques, it can only be restored to the designed level [4]. Design influences reliability via such considerations as stress margins used, margins to critical speeds, margins to blade and vane vibration frequencies, and environmental conditions including fuel, air, and oil specifications. The simplicity of the design, the design maturity, and established design and development procedures along with redundancy make an important contribution to engine reliability. Manufacture, quality control, and experience also make a major input. Often a reliable gas turbine can be let down because of inadequate installation and/or auxiliaries. An increase in reliability requires high developmental costs and then in order to maintain this reliability with time, good maintenance techniques are required (Fig 5). 


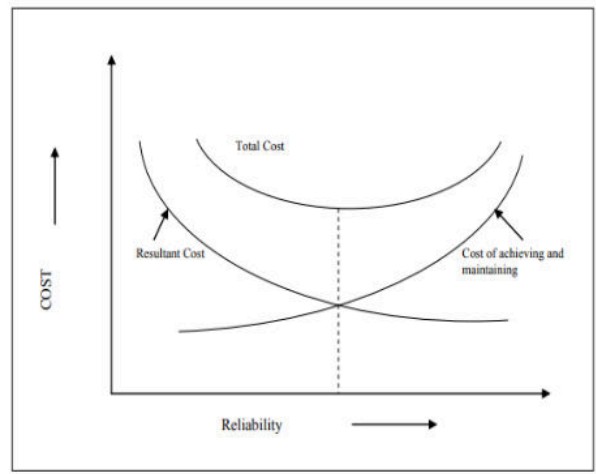

Figure 5 Cost/Reliability Relationship

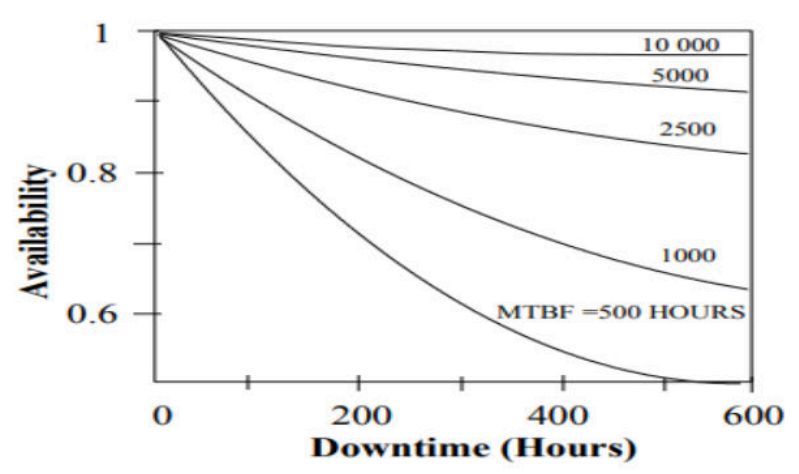

Figure 6 Relationship among MTBF, downtime, and availability

\subsection{Availability}

The largest contributors to forced outage rates are often engine support systems such as control and fuel systems [4]. The downtime associated with these systems can be managed to acceptable levels by design redundancy and the holding of appropriate spares. Advances in instrumentation and microprocessor-based controllers can be expected to contribute to further improvements in the availability of engine support systems.

Probability of being available, independent of whether the unit is needed- includes all period hours and mean time between failures [4] - units are \%:

$$
\text { Availability }=\frac{\text { MTBF }}{\text { MTBF+Downtime (2) } \quad(\text { Fig 6) }}
$$

MTBF = Mean time between failure and depends on the reliability Downtime $=$ Outage Hours

\subsection{Maintainability}

Maintainability may be defined as the ability to maintain aircraft and aero engines.

\section{GAS TURBINE FAULTS AND SYSTEMS MONITORING}

In service performance deterioration of gas turbine engines is inevitable [4]. Gas turbine engines operate over a wide range of temperatures, speeds, power, and environments. All these cause a deterioration of the gas turbine performance which can be defined as the cumulative effect of the performance degradation of various modules that constitute the engines [4].

GT Faults or Physical Problems (Fig 8) which have been shown in the below figure result in the degraded component performance and produce changes in the measured parameters. These measured parameters (Fig 7) would help in identifying the faults in the Aero Engine. However, certain faults go unnoticed due to negligible effects caused by the faults on the measurable parameters of the engine. In order to address this problem and for early failure detection of Aero Engine, engine monitoring techniques such as Oil System Monitoring, Debris Monitoring, Vibration Monitoring, Acoustics Monitoring, Visual Condition Monitoring, Turbine Exit Spread Monitoring, and Limited Transient Monitoring have been developed. An integrated diagnostic system based on these systems monitoring would improve the failure prediction of Aero Engines. 


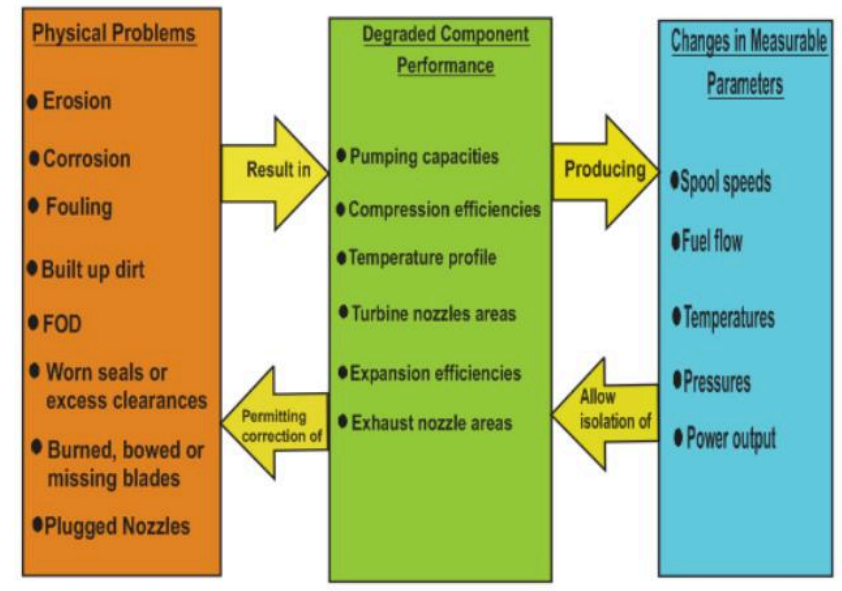

Figure 7 Engine fault and parameter relationship

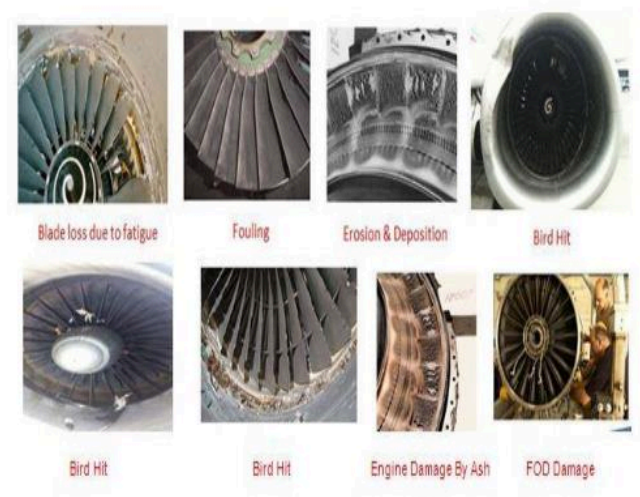

Figure 8 Types of Gas Turbine Faults

\section{CONDITION-BASED MAINTENANCE THROUGH CONDITION MONITORING}

Maintenance is planned dynamically on the basis of machine or system conditions. Conditionbased maintenance does have advantages compared to the other two strategies since modern measurement and signal-processing methods are used to accurately diagnose items/equipment during operation. However, it requires a reliable condition monitoring method. One area within this type of maintenance is condition monitoring that aims to continuously observe wear-related variables throughout a system's lifetime to determine its degree of deterioration.

For condition-based maintenance, the action taken after each inspection depends on the state of the system. It may involve no action, minimal maintenance to return the system to the previous stage of degradation, or major maintenance to bring the system to an as-good as-new state. For time-based preventive maintenance, preventive maintenance is carried out at predetermined time intervals to bring the system to an as-good-as-new state. The steps involved in carrying out Condition-based maintenance are given below (Fig 9).

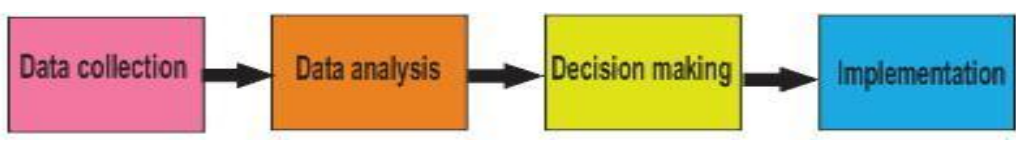

Figure 9 Condition-Based Maintenance Steps

\subsection{Data Collection}

The relevant data are collected through the use of process control systems, vibration measurements, oil sampling, and other methods. The two most common types of data are failure data and process data. Failure data are related to such things as vibration acoustics and the amount, type, and size of metal particles in lubrication oil, and are a direct expression of the failure mode of a component [3]. Process data relate to the output characteristics of the component (such as pressure, flow, and temperature) and can only be used indirectly to identify the failure mode.

\subsection{Data Analysis}

Depending on the situation, the data may need to be cleaned up. For example, during startups and shutdowns, the engine may exhibit erratic behavior, which is not to be misinterpreted as a failure. The data can be analyzed in several ways, for example by direct comparison with a 
threshold or by examining trends or unusual behavior. Two types of models are generally used for this purpose: analytical and statistical models [3]. Analytical models are cause-effect expressions of failure, whereas statistical models need historical data to calculate the probability of failure, along with the expected time to failure. Relating the process datafailure data dimension to the analytical model- the statistical dimension yields a typology of condition-based maintenance types.

\subsection{Decision Making}

Based on the data and the analysis, a decision is made. Such a decision may involve a change in operating routines or the direct execution of a maintenance task. It may also lead to additional data collection and analysis.

\subsection{Implementation}

Once a decision has been made, an intervention is planned. After the intervention, reports can be created and stored for future maintenance actions. Evaluations are conducted when deemed necessary.

\section{RUL AND ITS PREDICTION METHODOLOGIES AND TECHNIQUES}

The RUL of a system or a component is defined as the time period from the present time to the end of its useful life and can be used to characterize current health status (Fig 10). There are several approaches for determining the RUL of subsystems or components. These are categorized into different methodologies and techniques (Fig 11).
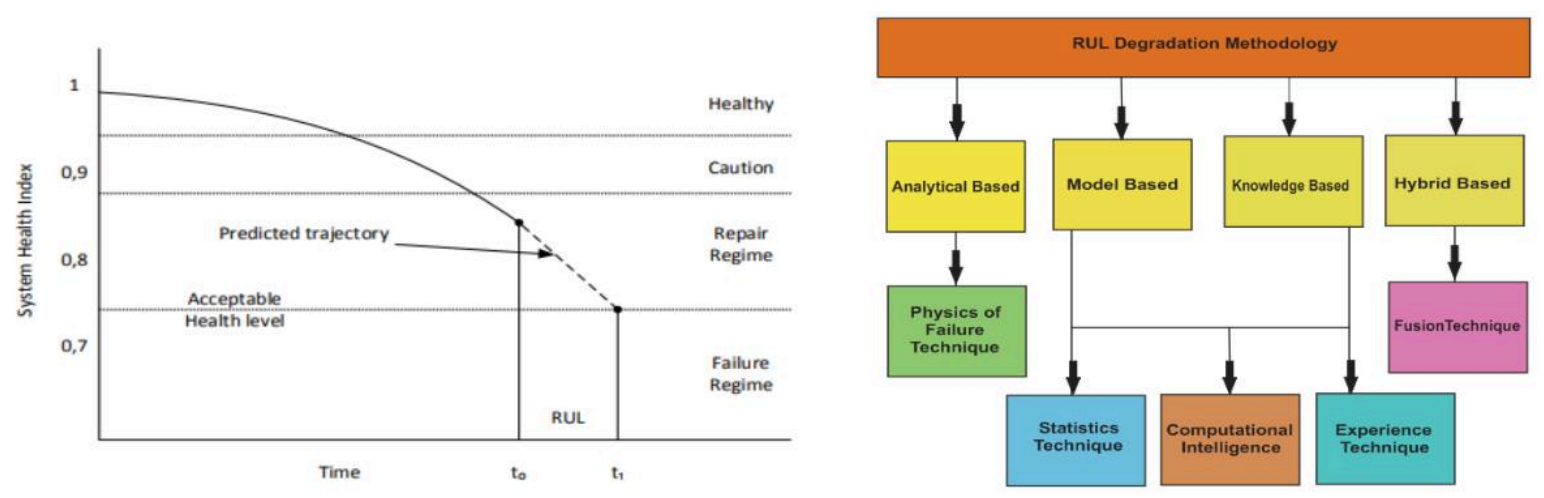

Figure 10 Definition of RUL

Figure 11 Taxonomy of RUL Prediction Methodologies and Techniques

\subsection{Prediction Methodologies}

Model-based: In this methodology, RUL predictions are based on statistics and approaches for computational intelligence. The models are derived from the configuration, usage, and historical run-to-failure data and are used in maintenance decision making. Components that are analyzed and documented in the literature include bearings and gear-plates from manufacturing industries. The model-based methodology is commonly used to estimate RUL and thereby base the maintenance decision based upon failure threshold [5].

Analytical-based: This approach for RUL prediction includes the physical failure technique and refers to an understanding of techniques that aid reliability estimates of the physics-based model. Failure events such as crack by fatigue, wear, and corrosion of components are based on mathematical laws used to estimate RUL. Analytical based models require the combination 
of experiments, observations, geometry and condition monitoring of data to estimate any damage in a specific failure mechanism.

Knowledge-based: This model uses a combination of computational intelligence and experience to predict RUL and relies on the collection of stored information from domain experts and interpretation of rules set.

Hybrid: A hybrid model is a collection methodology and technique. A hybrid model uses several techniques for RUL estimations and can include both parametric and non-parametric data to improve accuracy [5]. The different parameters predict RUL individually and methods based on probability theory facilitate the fusion of two or more RUL predictions results to achieve a new RUL.

\subsection{Prediction Techniques}

Statistics: This technique is based on past and present data that is analyzed with methods such as autoregressive moving average and exponential smoothing for effective prediction of result [5].

Experience: This technique makes use of expert judgments and knowledge, either explicit (easily transferred to others) or tacit (difficult to transfer to another person by means of writing it down or verbalizing it), that is gained from domain experts.

Computational Intelligence: This method is also known as soft computing and includes fuzzy logic and neural networks that are parameter-based and therefore dependent on input data to generate the desired output [5]. An artificial neural network uses data from continuous monitoring systems and requires training samples. The artificial neural network is a "blackbox" in the sense that it provides only little insight into the internal structures.

Physics of Failure: This technique needs parametric data and is based on approaches such as continuum damage mechanics, linear damage rules, non-linear damage curves, and two-stage linearization [5].

Fusion: This technique is based on the merging of multiple data sets into a refined state. The techique extracts pre-processes and fuses data for the accurate and fast forecast of RUL [5].

\section{OPTIMIZATION OF AERO ENGINE UTILIZATION THROUGH IMPROVED ESTIMATION OF REMAINING USEFUL LIFE (RUL) OF ON CONDITION (OC) PARTS}

The MROs and Aircraft Operators across the world face the challenge of low serviceability of aero engines, high lead time, and downtime of aero engines. The consequences of these challenges cause delays and cancellation of flights and lead to the poor combat readiness of military aircraft. The cancellation and delay of flight cause significant costs to the aircraft operator and poor readiness and responsiveness of military aircraft make the military and the country more unsecured and vulnerable to infiltration and terrorist attacks. It is revealed from the studies that the various causes of these problems are poor prognostics which lead to an increase in corrective maintenance and accidents, non-availability of spare parts and skilled manpower, poor prediction of RUL of OC parts, poor condition-based maintenance, and high lead time in fault diagnosis. Therefore, a need for this research on optimization has been identified to address the various problems the aerospace industry is facing with regard to aero engine maintenance.

The concept of optimization of Aero Engine Utilization has attracted worldwide attention in the field of Aviation Maintenance due to the various benefits associated with it. The various benefits are reduction of operation and maintenance costs, increase in availability and reliability of aero engines, reduction in lead time and downtime of aero engines, reduction in 
cancellation and delay of flights, increase in readiness of military aircraft for combat operations, and increase of customer satisfaction. The optimization techniques employed by various Maintenance Repair Overhauls (MROs) vary from MRO to MRO. This paper focuses on the Optimization of Aero Engines through a more accurate estimation of RUL of OC Parts and novel maintenance procedures and techniques.

An engine consists of three types of components. They are Life Limited Parts (LLP), OnCondition parts (OC parts), and Consumables [6]. Consumables are exchanged at specified maintenance occasions. The LLPs are safety-critical parts with a fixed lifetime while the OC parts are engine components that are not safety-critical. Components whose breakdown could cause an engine failure so serious that it could cause an aircraft crash are deemed to be LLPs [6]. Examples of LLPs are fan blades and disks, whereas OC parts are components like the low-pressure turbine case and the exhaust frame assembly.

Aircraft engines are brought into the Shop Floor/Engine Bay/Module Change Workshop for various reasons. They are during unscheduled or corrective maintenance, routine/scheduled maintenance, life expiry of module or component, the heavy landing of aircraft, modifications, and major rectification. The main reason for taking an engine to the workshop for maintenance is that an LLP has reached its life limit and needs to be replaced or serviced. The engines received in workshops are assessed by technicians/engineers according to the type of maintenance they require and accordingly a maintenance action is carried out which includes rectification or replacement of a component/part. During maintenance, the workshop technicians must decide which components to maintain including both LLPs and OC parts. Deciding to change/replace an LLP is comparatively uncomplicated as its life is given/mentioned in the maintenance manuals and Component Life Record (CLR) by the Original Equipment Manufacturer (OEM). Whereas the OC part does not have life and its replacement currently is purely based on historical data of the component and the technician who is assessing the component/part. Therefore, the replacement of OC Part and its estimation of RUL require a model that is based on a methodical approach.

\subsection{Improved Life Calculation of an LLP}

For an aircraft engine, a cycle can be defined as the period during which a particular engine parameter moves between two predefined limits. The number of cycles an LLP has consumed depends on the circumstances under which the engine has been used. For example, an engine that has been exposed to higher loads from air-to-air or air-to-surface missions is likely to have consumed more life than an engine on reconnaissance missions. Similarly, in an engine exposed to combat mode and higher loads, higher temperatures and pressures are likely to consume more cycles than an engine that is used for transportation. In the same way, a commercial aircraft engine used in an area with many high mountains requiring it to climb rapidly to cruising altitude is likely to consume more life than an engine in a normal environment.

Most of the MROs/Airlines across the world regardless of Civil or Military Aviation do not include the actual cycles based on the loads experienced by the engine in their record of flying hours which reflects the life of the LLP. In most of the maintenance establishments or airlines, every mission or sortie or flight is assumed as a normal flight and logged in the flying records. A flight that has flown for 2 hours over hilly terrain is logged as 2 hours only like a normal flight although the actual cycles would be much more and equal to 3 hours. This will have a significant impact on flight safety as there are chances of using the component beyond its life which may lead to a catastrophic failure of the engine or an inflight shutdown. The vice versa is also true as there would be occasions when the hours logged is more than the actual hours as the logging does not take into account the actual cycles. In this case, a 
component although it has some more life left can be withdrawn before its actual life expiry which results in an increase in maintenance, loss of man-hours, an increase in downtime and lead time, and eventually an increase in maintenance costs and delays and cancellation of flights.

This Paper recommends the Life Tracking System (LTS) introduced and employed by GKN Aerospace for the calculation of the life consumption of LLPs. The LTS (Fig 12) uses the actual data for each mission flown rather than a standard or normal mission [2]. The calculations are based on engine parameters and data from each mission to determine how many life cycles have been consumed by each mission or flight. The accuracy of the life predictions has been improved by reducing one of the most significant uncertainties in the life analysis chain with regard to the uncertainty of the loads experienced [2]. The reduced uncertainty with LTS provides an opportunity to reduce safety margins without compromising airworthiness (Fig 12). The life consumption calculations are important as the results influence the status of the LLPs. In the event that nothing unexpected and unforeseen occurs, the LTS calculation identifies the next maintenance interval. However, although LTS reduces the uncertainty about the load situation for each individual component, the future missions or flights and the loads that it will experience in future flights is not known in advance unless it uses same flight profiles like airlines and this makes it difficult more difficult to predict when the next maintenance will occur.
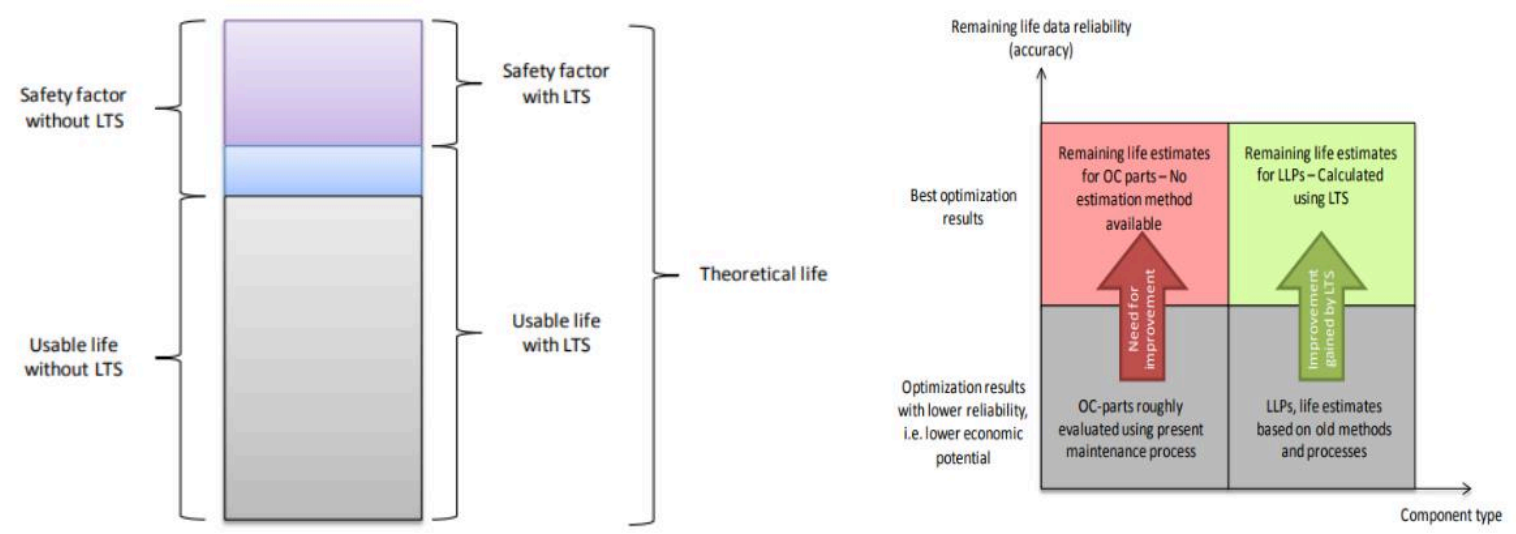

Figure 12 Life Tracking System Figure 13 Current Status of Estimation of RUL of Aero Engine Parts

It has been found that the main source of the cost savings from using LTS is a result of components on average being used longer (Fig 13). The savings are especially significant when the life limit of some LLPs can be extended beyond the expected lifespan of the engines based on the current system [2].

\subsection{Improved Estimation of RUL of OC Parts Using a Standardized Replacement Model}

OC parts, the other category of components in an aircraft engine, are evaluated against their maintenance manual that contains approved deviations from OC-parts state when it is new [6]. A component is either approved for continued operation or not. The remaining flight hours for OC parts are never estimated. Currently, life length estimates based on historical failure data (allowable flight hours) is primarily used to predict future demand for spare parts and to carry out maintenance [6]. This uncertainty or inability to estimate accurate RUL of OC Parts leads to either removal of the component much before the actual expiry or continuation of the component after its expiry which will have a significant impact on the flight safety and maintenance costs. In addition to this, the maintenance planning lacks 
consistency during the replacement of OC Parts as the decision to replace a part is largely based on the technician who does not have a standard maintenance procedure based on a systematic and methodical approach to follow. Also, the decision to replace a part varies from technician to technician which results in highly inconsistent maintenance planning/schedule.

Therefore, there is a need to introduce a model (Fig 15) which is based on a methodical approach to address this problem. This paper introduces a standardized replacement model for improved estimation of RUL of OC Parts (Fig 15).

\subsection{Standardized Replacement Model (SRM)}

The Standardized Replacement model (Fig 15) has been proposed considering not only historical data (Fig 14) which is being used currently but also the data acquired from flight analysis which includes flight profiles, analytical data which contains various parameters of the engine. Based on this integrated data (Fig 14) a standard for different OC Parts is mentioned in the Component Maintenance Manual (CMM) or a concerned manual made by OEM. This approved standard is considered as Standardized Replacement Model and is regularly modified or upgraded according to the operations and modifications that the engine undergoes during its Service as part of Continuous Improvement. In addition to this, various tests which involve crack or damage identification are also included in this maintenance model.

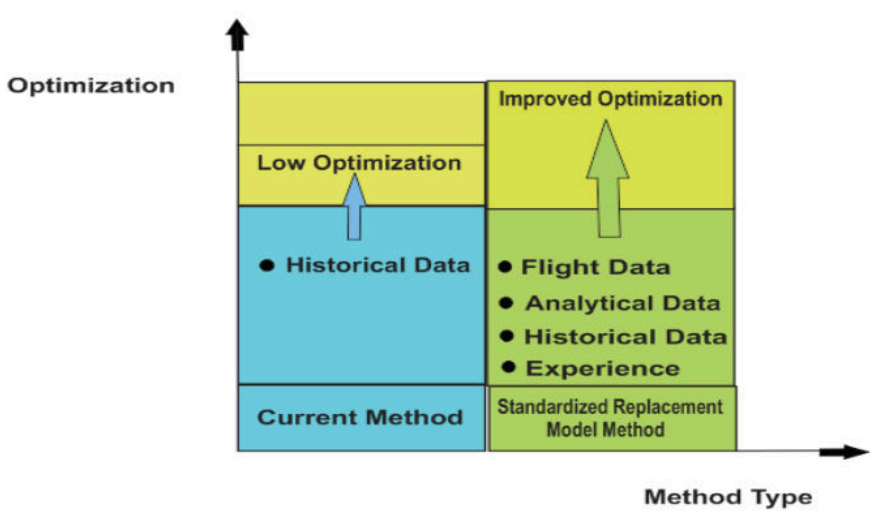

Figure 14 Comparison of Current and SRM Method Optimization

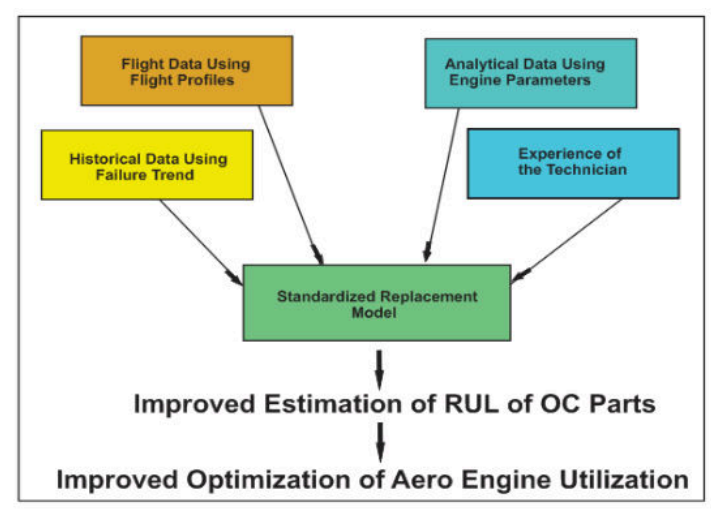

Figure 15 Standardized Replacement Model (SRM)

The maintenance as per this model requires an OC Part to be periodically inspected and checked against the physical standard mentioned in the manual to determine whether it can continue in service or not. The purpose of this is to remove the part before its failure during various operations. This model helps to determine which components should be replaced at an actual maintenance occasion based on the data acquired. This model is able to calculate the optimum balance between the remaining life of the engine components and the costs for each maintenance interval versus the cost of the component and their exchange. This creates a maintenance plan with as few maintenance events as possible without compromising on safety. Estimation of RUL for OC Parts is improved with this model as it uses a classification method that classifies the components into different life length groups depending on the fault modes and the status of components. The estimated RUL for each component could then be used to indicate a more accurate RUL of each OC Part so that the component can be effectively used for various operations. These classified OC parts would also make it easier for a technician to ensure that the correct maintenance activities are performed at each maintenance interval. The benefit from this is the maintenance interval between maintenance events increases because the standardized replacement model is based on more reliable input data. 


\section{DISCUSSION}

There is a continuous evolvement that is taking place on various aspects in the field of maintenance due to intense competition between various airlines and MROs across the aerospace industry to capture the market share. A conscious effort has been put in this paper to make the reader understand those developments with regard to the maintenance and optimization of Aero Engine Utilization. Coherence has been developed in this paper to provide a good insight into the subtleties with regard to the optimization. The types of maintenance have been mentioned to explain the developments that are occurring in the way the maintenance is carried out. Maintenance types like condition-based and opportunity-based have evolved to increase the utilization of Aero Engine and therefore emphasis has been given on this. The subtle differences between Maintainability, Availability, and Reliability have been made clear and their importance from the maintenance and optimization perspective has been brought out. The types of Gas Turbine (GT) Faults, how they are caused, and what kind of impact it will have on component performance and various parameters of the engine have been emphasized to explain how degradation and deterioration occur in Aero Engines. Systems Monitoring which is used to identify the deterioration of Aero Engine has also been given importance in this paper. The various prediction methodologies and techniques which are used to predict RUL of parts or components have been explained to make the reader understand how the prediction helps to identify and diagnose a serious problem of an LLP or OC Part in advance although the LLP has not reached its life expiry and may be continued in service which might have led to a serious accident if not diagnosed using these prediction methodologies and techniques. Improved life calculation of an LLP using LTS (Fig 12) has been proposed to have more consistency in the calculation of an LLP which may decrease downtime of Aero Engine. This study has found that there is scope for optimization of Aero Engine use through improved estimation of RUL of OC Parts as the absence of a standardized model for estimation of RUL of OC Parts could decrease the availability of Aero Engines for various operations (Fig 13). It is found from the research that most of the MROs do not employ any model which focuses on estimation RUL of OC Parts. It is proposed in this paper a standardized Replacement Model for estimation of RUL of OC Parts could optimize the Aero Engine Utilization of Aero Engine.

\section{CONCLUSION}

There has been a significant improvement in the performance of the Aero Engines in the last few decades with regard to speed, power, and economy due to developments in the design and manufacturing of Aero Engines. However, the development in the maintenance does not commensurate with the design and manufacturing although some improvements have taken place in the way maintenance is carried out. It is found from the study that most of the MROs/Airlines do not use availability and reliability calculations to quantify the serviceability of their fleets. It is proposed the inclusion of availability and reliability in the maintenance planning would help in optimizing the Aero Engine Utilization. It is found from the study that the degradation of components is largely caused by GT Faults and adherence to Systems Monitoring according to Maintenance Manuals would help in identifying early failure of the systems.

It is suggested that the introduction of prediction methodologies and techniques for calculation of RUL of parts would help to identify any departures from the performance of Aero Engines. Condition-based monitoring is based on this. It is proposed that improved calculation of life consumption of an LLP using LTS and improved estimation of RUL of OC Parts using Standardized Replacement Model would contribute to the Optimization of Aero Engine Utilization. This study recommends equal attention to maintenance with that of design 
and manufacturing of Aero Engines both in the design stage and during after-sales service by the OEM would help to improve Availability, Reliability, and Safety of Aero Engines.

\section{ACKNOWLEDGEMENTS}

I am greatly indebted and express my gratitude to M Zakria Baig, Retired Principal, Government Polytechnic College, Anantapur, Dr. K Venkatasubramanian, BITS, Pilani, Prof (Retd Group Captain) Deepak Bana, RV College of Engineering, Dr. Sripad Devalkar, Associate Professor, ISB, Prof Iain Gray, Director, Aerospace, Cranfield University, Prof Pilidis, Head of Propulsion Engineering Centre, Cranfield University, Dr. Suresh Sampath, Dr. Li, Dr. Devaiah Nalianda, Dr. Igie, Dr. Amir, Dr. Panos, Dr. Soheil Jafari, Dr. Azaika, Mrs. Claire Bellis, Mrs. Suzanne and faculty members, Centre for Propulsion Engineering and Centre for Aeronautics, Cranfield University for their constant encouragement and guidance in my research. Also, I am thankful and grateful to my colleagues for their motivation and support in this endeavor.

\section{REFERENCES}

[1] V.K.Shanmuganathan, Dr. A.P. Haran, S. Ragavendran, N. Gayathri, 2013, Aero-Engine Maintenance Cost Optimization by RCM, Life Science Journal

[2] Veronica Fornlof, 2016, Improved Remaining Useful Life Estimations for On Condition Parts in Aircraft Engines, PhD Thesis, Skovde University, Sweden

[3] Jardine, A. K. S., Lin, D. \& Banjevic, D. 2006, A review on machinery diagnostics and prognostics implementing condition-based maintenance, Mechanical Systems and Signal Processing, 20, 1483-1510.

[4] Dr. Y Li, Gas Turbine Diagnostics Notes, Cranfield University

[5] Okoh, C., Roy, R., Mehnen, J. \& Redding, L. 2014, Overview of Remaining Useful Life Prediction Techniques in Through-life Engineering Services, Procedia CIRP, 16, 158-163.

[6] Fornlof, V., Galar, D., Syberfeldt, A. \& Almgren, T. 2015, Aircraft engines: A maintenance trade-off in a complex system, International conference on quality, reliability, infocom technology and business operations, New Delhi, India.

[7] Harry A. Kinnison, Ph. D, 2013, Aviation Maintenance Management, Second Edition, McGraw Hill Education.

[8] Fornlof, V., Galar, D., Syberfeldt, A. \& Almgren, T. 2016. On Condition Parts versus lifelimited parts: A trade-off in aircraft engines. In: Kumar, U., Ahmadi, A., Verma, K. A. \& Varde, P. (eds.) International conference on reliability, safety, and hazard Advances in reliability, Maintenance, and Safety. Lulea, Sweden: Springer International Publishing

[9] Almgren, T., Andréasson, N., Anevski, D., Patriksson, M., Stromberg, A.-B., and Svensson J.(2008), "Optimization of opportunistic replacement activities: A case study in the aircraft industry", Preprint 2008:45, Dept. of Mathematical Sciences, Chalmers Univ. of Tech. and Univ. of Gothenburg, Goteborg Sweden

[10] Beata Mrugalska, 2018, Remaining Useful Life as Prognostic Approach: A Review, Springer, IHSED

[11] Jing Cai, Xin Li, and Xi Chen, 2016 optimization of Aero engine Shop Visit Decisions Based on Remaining Useful Life and Stochastic Repair Time, Mathematical Problems in Engineering, Hindawi Publishing Corporation 
[12] Mustagime Tulin Yildirim, Bulent Kurt, 2018, Aircraft Gas Turbine Engine Health Monitoring System by Real Flight Data, International Journal of Aerospace Engineering, Hindawi Publishing Corporation

[13] Almgren T., Andréasson, Patriksson, 2012, Optimization models for improving periodic maintenance schedules by utilizing opportunities, Conference Paper, Chalmers University of Technology

[14] Hariharan Hanumanthan, (2009), Severity Estimation and Shop Visit Prediction of Civil Aircraft Engines, $\mathrm{PhD}$ Thesis, Cranfield University

[15] Ahmed Mosallam, 2014, Remaining useful life estimation of critical components based on Bayesian Approaches, PhD Thesis, Universite de Franche-Comte

[16] C. Okoh, R. Roy, J. Mehnen, 2016, Predictive Maintenance Modelling for Through-Life Engineering Services, The 5th International Conference on Through-life Engineering Services

[17] Treager, Third Edition, 1997 Aircraft Gas Turbine Engine Technology, Tata McGraw Hill

[18] Fornlof, V., Galar, D., Syberfeldt, A. \& Almgren, T. 2015, RUL estimation and maintenance optimization for aircraft engines: A system of system approach, International Journal of System Assurance Engineering and Management.

[19] Kroes, Wild, Seventh Edition, 2010, Aircraft Power plants, Tata Mc Graw Hill

[20] Lufthansa Technical Training (July 1999), Training Manual, A319/A320/A321, ATA 7180, CFM 56-5A

[21] Boyce, M. P. (2006) 'Maintenance techniques', in Gas Turbine Engineering Handbook.

[22] Soares, C. (2015) 'Maintenance, repair and overhaul', in Gas Turbines: A Handbook of Air, Land and Sea Applications, pp.494-542.

[23] Volponi, A. J. (2014) 'Gas turbine engine health management: Past, present, and future trends', Journal of Engineering for Gas Turbines and Power, 136(5), p. 051201.doi: 10.1115/1.4026126.

[24] Harrison, M. (2016) 'MRO forecast and market trends', in IATA 12th Maintenance Cost Conference.

[25] Naeem, M., Singh, R.and Probert, D (1998), "Implications of engine deterioration for the operational effectiveness of a military aircraft", Applied Energy, Vol.60, pp.115-152

[26] U.Igie, (2016), Evaluating Gas Turbine Performance Using Machine Generated Data: Quantifying Degradation and Impacts of Compressor Washing, Journal of Engineering for Gas Turbines and Power. 
2020-05-31

\section{Optimization of aeroengine utilization}

through improved estimation of

remaining useful life (RUL) of on

condition $(\mathrm{OC})$ parts

\section{Vidyasagar, Kotha}

International Association of Engineering and Management Education (IAEME)

Vidyasagar K (2020) Optimization of aeroengine utilization through improved estimation of remaining useful life (RUL) of on condition (OC) parts. International Journal of Mechanical Engineering and Technology (IJMET), Volume 11, Issue 5, 2020, pp.34-47

http://www.iaeme.com/MasterAdmin/Journal_uploads/IJMET/VOLUME_11_ISSUE_5/IJMET_11_05_004.pdf Downloaded from Cranfield Library Services E-Repository 